\title{
Parafoveolar retinoblastoma regression with foveal preservation following intra-arterial chemotherapy documented on hand-held optical coherence tomography in a newborn
}

Vera Yarovaya, Kareem Sioufi and Carol L. Shields ${ }^{*}$

\begin{abstract}
Background: Optical coherence tomography (OCT) has become an invaluable tool in retinoblastoma management, providing submillimeter visualization of tumor control following treatment. Herein, we document OCT-detection of a subtle tumor recurrence, allowing early intervention and achieving foveal microanatomy preservation.

Case presentation: A 3-week-old girl was diagnosed with bilateral familial retinoblastoma, classified as group D in the right eye (OD) and group B in the left eye (OS), and treated with intravenous chemoreduction. At 6-months follow-up, the right eye was under control, but the left eye revealed a subtle juxtafoveal tumor recurrence, documented on handheld OCT (HH-OCT) and measuring $2750 \mu \mathrm{m}$ in diameter and $792 \mu \mathrm{m}$ in thickness. Treatment with intraarterial chemotherapy (IAC) using 1 cycle of melphalan $5 \mathrm{mg}$ was performed and complete tumor control was achieved, leaving a flat, concave scar $663 \mu \mathrm{m}$ from the intact foveola and measuring $2750 \mu \mathrm{m}$ in diameter and $120 \mu \mathrm{m}$ in thickness. Foveal microanatomy OS was preserved on $\mathrm{HH}-\mathrm{OCT}$. The findings remained stable at 2 years following IAC.
\end{abstract}

Conclusions: $\mathrm{HH}-\mathrm{OCT}$ is an important tool in retinoblastoma management. In this case, $\mathrm{HH}-\mathrm{OCT}$ allowed for early detection of retinoblastoma recurrence, before foveal invasion. Following treatment with IAC, complete tumor regression was noted and foveal microanatomy remained intact.

Keywords: Eye, Retina, Retinoblastoma, Optical coherence tomography (OCT), Intra-arterial chemotherapy, Foveola, Fovea

\section{Background}

Optical coherence tomography (OCT) has become an invaluable tool for in vivo evaluation of the microstructure of the retina and choroid. This technology employs light scatter to create a 2-dimensional cross-sectional image of the human fundus, initially described by Huang et al. [1]. With advancements in technology and development of spectral-domain (SD-OCT), high resolution in vivo evaluation of retinal microanatomy in healthy and diseased eyes now approaches resolution of tissue histology. The subspecialty of ocular oncology has

*Correspondence: carolshields@gmail.com

Ocular Oncology Service, Wills Eye Hospital, Thomas Jefferson University,

840 Walnut Street, Suite 1440, 14th Floor, Philadelphia, PA 19107, USA incorporated SD-OCT into practice for the study of the structure of various retinal, choroidal, optic disc, and scleral tumors and their relationship to other structures [2]. Handheld OCT (HH-OCT), a portable, SD-OCT unit that can be used in the operating room, has become a crucial diagnostic tool in pediatric retinal diseases as it provides accurate localization of disease processes and is completely noninvasive [3]. HH-OCT is also used in the management of retinoblastoma, providing submillimeter visualization of tumor development and regression, far beyond the detection by ophthalmoscopy. In addition, this technology allows for detection of invisible tumors $[4,5]$, and monitoring of foveal microanatomy for visual prognostication [6]. 
Herein, we report the case of a 3-week-old girl with bilateral familial retinoblastoma treated with systemic chemoreduction. Tumor recurrence was confirmed on $\mathrm{HH}-\mathrm{OCT}$ and was subsequently controlled with intraarterial chemotherapy (IAC). Documentation with $\mathrm{HH}-$ OCT allowed accurate monitoring of the tumor as well as the foveola.

\section{Case presentation}

A 3-week-old girl, with a family history of maternal unilateral retinoblastoma, presented for evaluation of leukocoria right eye (OD). On examination, visual acuity was fix and follow in both eyes (OU) and intraocular pressures were normal OU. External examination documented obvious leukocoria OD. Fundus evaluation OD revealed a white macular tumor measuring $16.0 \mathrm{~mm}$ in largest basal dimension and $6.1 \mathrm{~mm}$ in thickness, and with overlying mild vitreous seeding and surrounding extensive serous retinal detachment. Fundus evaluation of the left eye (OS) detected a solitary mass measuring $2.0 \mathrm{~mm}$ in basal dimension and $1.0 \mathrm{~mm}$ in thickness, located within $2.0 \mathrm{~mm}$ from the foveola. A diagnosis of bilateral familial retinoblastoma, group D OD and group $\mathrm{B}$ OS, was rendered and treatment with intravenous chemoreduction (CRD) using vincristine, etoposide, and carboplatin was initiated. Following therapy with individual tumor consolidation, all retinoblastomas were regressed.

At 6-months follow-up, the right eye remained under control, but the left eye revealed a subtle recurrence of the juxtafoveal tumor (Fig. 1a) and HH-OCT (iVue Optovue, Fremont, $C A$ ) revealed an intact macula with adjacent tumor recurrence (Fig. 1b), measuring $2750 \mu \mathrm{m}$ in diameter and $792 \mu \mathrm{m}$ in thickness. The recurrence was $615 \mu \mathrm{m}$ from the foveola. Treatment with intraarterial chemotherapy (IAC) using Melphalan $5 \mathrm{mg}$ was

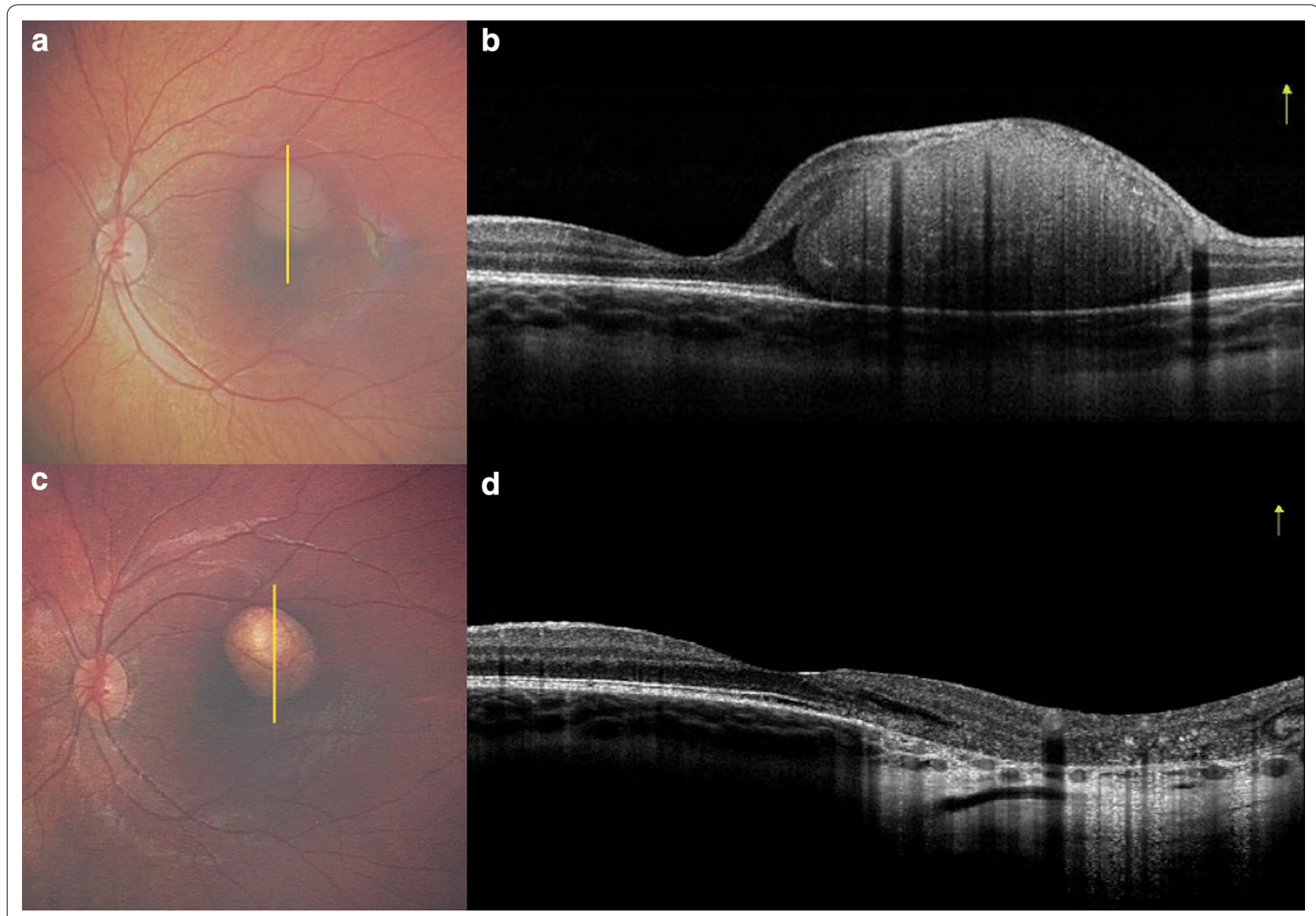

Fig. 1 Documentation of retinoblastoma control using spectral domain hand-held optical coherence tomography (HH-OCT). Following 6 cycles of intravenous chemotherapy for bilateral retinoblastoma, the left eye demonstrated small dome-shaped, outer retinal tumor recurrence (a) of $2750 \mu \mathrm{m}$ in basal dimension and $792 \mu \mathrm{m}$ thickness in the parafoveolar region, documented on HH-OCT (b) and with adjacent shallow subretinal fluid. The mass was $615 \mu \mathrm{m}$ from the foveola. Following 1 cycle of intraarterial chemotherapy, the tumor showed complete regression (c) and $\mathrm{HH}$ OCT (d) documented a concave scar of $120 \mu \mathrm{m}$ in thickness and located $663 \mu \mathrm{m}$ from foveola. There was OCT light transmission through atrophic retinal pigment epithelial accentuating the underlying thin choroid. The foveola remained intact 
performed and complete tumor control was achieved with 1 cycle (Fig. 1c), leaving a concave scar of $2750 \mu \mathrm{m}$ in diameter and $120 \mu \mathrm{m}$ in thickness, located $663 \mu \mathrm{m}$ from the foveola. In addition, there was underlying choroidal thinning and preservation of the foveal microanatomy documented by HH-OCT OS (Fig. 1d). The findings remained stable on last follow-up at 2 years following IAC.

\section{Discussion and conclusions}

Chemotherapy is a first-line globe-sparing therapy for retinoblastoma and can be delivered through intravenous, intraarterial, sub-Tenon fascia, and intravitreal routes [7]. IAC has assumed a major role in retinoblastoma management, achieving globe salvage and resolution of retinal detachment with minimal systemic toxicities $[8$, 9]. Studies have documented that IAC can be employed as a primary treatment or secondary (rescue) treatment for eyes that fail alternative therapies [10]. Overall, IAC achieves retinoblastoma control with globe salvage in $72 \%$ of eyes as a primary therapy and $62 \%$ of eyes when used as secondary therapy [10]. Our patient had initial treatment with intravenous chemotherapy and was secondarily treated with IAC, achieving immediate tumor control, and with foveolar preservation, despite the proximity of the tumor within $615 \mu \mathrm{m}$ to the foveola.

Imaging of retinoblastoma includes digital wide-field fundus photography, fluorescein angiography, ultrasonography, and now HH-OCT. In this case we used the stand-mounted iVue Optovue (Optovue, Freemont, CA) to capture the tumor. The iVue provides up to $21^{\circ}$ field of view and can be mounted on a wheeled stand which offers stability when acquiring OCT images during examination under anesthesia. HH-OCT scans using iVue can be captured with minimal pupillary dilation but a fully dilated pupil yields better results. HH-OCT provides precise submillimeter tumor documentation within the retina and even into the choroid $[4,11,12]$. In fact, $\mathrm{HH}-\mathrm{OCT}$ can provide detection of "invisible" retinoblastoma, first reported by Saktanasate et al. in which a subclinical tumor was coincidentally captured on $\mathrm{HH}-\mathrm{OCT}$ in the macular region, and localized to the outer nuclear layer [4]. Berry et al. later demonstrated the use of SDOCT to identify subclinical retinoblastoma, estimating that this technology could allow earlier diagnosis and treatment with less treatment-related damage to ocular structures and more careful surveillance [11]. Soliman et al. evaluated the use of $\mathrm{HH}-\mathrm{OCT}$ in 63 eyes and found that in $339 \mathrm{HH}-\mathrm{OCT}$ sessions $92 \%$ were informative, of which OCT directed diagnosis in $16 \%$ and treatment in 58\% [13]. They also noted that OCT influenced preOCT treatment plans in $15 \%$ of all OCT sessions. In this case, we confirmed clinical suspicion of recurrence using
HH-OCT documenting a homogenous dome-shaped intraretinal mass with inner retinal draping over the solid tumor. We subsequently documented complete tumor response to IAC with OCT-evidence of concave regression and preservation of the foveola, despite the parafoveolar tumor location.

In our case, tumor recurrence was detected early with $\mathrm{HH}-\mathrm{OCT}$, allowing intervention with IAC for complete tumor regression and preservation of the foveal microanatomy. In most cases, 3 cycles of IAC are necessary for tumor control, but given the submillimeter recurrence, only 1 cycle was necessary to achieve control with no further recurrence on 2-year follow-up.

In summary, HH-OCT is an invaluable tool in retinoblastoma management, providing information that aids treatment decisions, particularly in juxtafoveal tumors. The role of HH-OCT in retinoblastoma management includes detection of subclinical new tumors, monitoring of tumor regression, detection of small tumor recurrence, and judgment of foveolar microanatomy with estimation of visual potential in a preverbal child.

\section{Abbreviations \\ OD: Right eye; OS: Left eye; OU: both eyes; OCT: Optical coherence tomog- raphy; SD-OCT: Spectral-domain optical coherence tomography; $\mathrm{HH}-\mathrm{OCT}$ : Handheld optical coherence tomography; IAC: Intraarterial chemotherapy; CRD: Chemoreduction.}

\section{Authors' contributions}

VY manuscript writing and reviewing. KS interpreting patient images and contributor in writing and reviewing the manuscript. CLS contributor in writing and reviewing the manuscript. All authors read and approved the final manuscript.

\section{Acknowledgements}

None.

Competing interests

The authors declare that they have no competing interests.

Availability of data and materials

Data sharing is not applicable to this article as no datasets were generated or analyzed during the current study.

Consent for publication

Consent to publish was obtained.

Ethics approval and consent to participate

Institutional review board approval was waived for this case report.

Funding

Support provided by Eye Tumor Research Foundation, Philadelphia, PA (CLS).

\section{Publisher's Note}

Springer Nature remains neutral with regard to jurisdictional claims in published maps and institutional affiliations.

Received: 11 July 2017 Accepted: 9 October 2017

Published online: 13 November 2017 


\section{References}

1. Huang D, Swanson EA, Lin CP, et al. Optical coherence tomography. Science. 1991;22(254):1178-81.

2. Shields CL, Pellegrini M, Ferenczy SR, Shields JA. Enhanced depth imaging optical coherence tomography of intraocular tumors: from placid to seasick to rock and rolling topography — the 2013 Francesco Orzalesi Lecture. Retina. 2014;34:1495-512.

3. Mallipatna A, Vinekar A, Jayadev C, et al. The use of handheld spectral domain optical coherence tomography in pediatric ophthalmology practice: our experience of 975 infants and children. Ind J Ophthalmol. 2015;63:586-93.

4. Saktanasate J, Vongkulsiri S, Khoo CT. Invisible retinoblastoma. JAMA Ophthalmol. 2015;133:e151123.

5. Rootman DB, Gonzalez E, Mallipatna A, et al. Hand-held high-resolution spectral domain optical coherence tomography in retinoblastoma: clinical and morphologic considerations. Br J Ophthalmol. 2013;97:59-65.

6. Cao C, Markovitz M, Ferenczy S, Shields CL. Hand-held spectral-domain optical coherence tomography of small macular retinoblastoma in infants before and after chemotherapy. J Pediatr Ophthalmol Strabismus. 2014;1(51):230-4.
7. Shields CL, Lally SE, Leahey AM, et al. Targeted retinoblastoma management: when to use intravenous, intra-arterial, periocular, and intravitrea chemotherapy. Curr Opin Ophthalmol. 2014;25:374-85.

8. Shields JA, Shields CL. Retinoblastoma. In: Intraocular tumors. An atlas and textbook. 3rd edition. Philadelphia: Lippincott Wolters Kluwers; 2016;311-34

9. Kaliki S, Shields CL. Retinoblastoma: achieving new standards with methods of chemotherapy. Ind J Ophthalmol. 2015;63:103-9.

10. Shields CL, Manjandavida FP, Lally SE, et al. Intra-arterial chemotherapy for retinoblastoma: outcomes based on the international classification of retinoblastoma. Ophthalmology. 2014;121:1453-60.

11. Berry JL, David Cobrinik D, Kim JW. Detection and intraretinal localization of an 'Invisible' retinoblastoma using optical coherence tomography. Ocul Oncol Pathol. 2016;2:148-52.

12. Shields CL, Mashayekhi A, Luo CK, et al. Optical coherence tomography in children: analysis of 44 eyes with intraocular tumors and simulating conditions. J Pediatr Ophthalmol Strabismus. 2004;41:338-44.

13. Soliman SE, VandenHoven C, MacKeen LD, Héon E, Gallie BL. Optical coherence tomography guided decisions in retinoblastoma management. Ophthalmology. 2017;124:859-72.

\section{Submit your next manuscript to BioMed Central and we will help you at every step:}

- We accept pre-submission inquiries

- Our selector tool helps you to find the most relevant journal

- We provide round the clock customer support

- Convenient online submission

- Thorough peer review

- Inclusion in PubMed and all major indexing services

- Maximum visibility for your research

Submit your manuscript at www biomedcentral com/submit 